\title{
Osmotic condition, buoyancy change and mortality in larval cod Gadus morhua. A bioassay for assessing near-term mortality
}

\author{
Matthew Sclafani*, Gray Stirling, William C. Leggett** \\ McGill University, Department of Biology, 1205 Dr. Penfield Ave., Montreal, Quebec H3A 1B1, Canada
}

\begin{abstract}
In larvae of marine fish, density differences are known to be associated with nutritional state and osmotic failure. We hypothesized that these density measures can be used to predict the nearterm mortality of larvae. Specifically, we predicted increased larval mortality to be positively and continuously associated with increased larval density. Under controlled conditions, we measured (1) the average density $\left(\mathrm{g} \mathrm{cm}^{-3}\right)$ and daily percent mortality of fed and starved larval cod Gadus morhua L. in culture tanks and (2) the relationship between larval density and percent mortality of both fed and starved larvae whose survival was monitored for a $24 \mathrm{~h}$ period following density determination. We observed a strong, positive linear relationship between average larval density and average percent mortality in both experiments $\left(\mathrm{r}^{2}=0.79\right.$ and $\mathrm{r}^{2}=0.78$ respectively). The regression slopes did not differ significantly between experiments. A linear regression on the pooled data yielded a highly significant relationship $\left(r^{2}=0.77, p<0.0001\right)$. A second-order polynomial regression was also significant and improved the fit $\left(R^{2}=0.80, p<0.0001\right)$. While the second-order polynomial regression better described the functional relationship between average density and average mortality, the simpler first-order model was judged preferable for predicting near-term mortality. The consistency and strength of the linear regressions suggests that larval density can be a reliable predictor of larval mortality. We determined the density of larvae associated with $50 \%$ mortality (potential 'critical' density value) using linear, polynomial and logistic regressions. All 3 produced similar 'critical' densities and we used the linear model to estimate this value. Larval cod having densities $>1.0338 \mathrm{~g} \mathrm{~cm}^{-3}$ have a $50 \%$ probability of dying within $24 \mathrm{~h}$. The potential for using larval density to predict the probability of near-term mortality in laboratory and field studies is discussed.
\end{abstract}

KEY WORDS: Larval fish $\cdot$ Buoyancy $\cdot$ Condition indices $\cdot$ Mortality $\cdot$ Bioassay $\cdot$ Cod

\section{INTRODUCTION}

A large number of indices have been developed with the goal of assessing the nutritional condition of larval fish (reviewed by Ferron \& Leggett 1994). These indices have been used to distinguish well-nourished ('good condition') larvae, from those that are starving (i.e. in 'poor condition'; see Theilacker 1978, 1986,

Present addresses:

- New York State Department of Environmental Conservation, Division of Fish, Wildlife and Marine Resources, 205 North Belle Meade Rd., Suite 1, East Setauket, New York 11733, USA.E-mail: mjsclafa@gw.dec.state.ny.us

-Queen's University, Department of Biology, Kingston, Ontario K7L 3N6, Canada
O'Connell 1980, 1981, Clemmesen 1987, 1993, Bisbal \& Bengtson 1995, Lochmann et al. 1995). These classifications are typically employed in an effort to estimate the susceptibility of larvae to starvation, which has been hypothesized to be an important source of in situ mortality (reviewed by Leggett \& Deblois 1994). The ultimate goal is to establish reliable relationships between larval condition, larval abundance and yearclass strength (O'Connell 1981, Theilacker 1986). However, Ferron \& Leggett (1994) identified few, if any, studies that had succeeded in relating condition indices to the probability of mortality or to fluctuations in year-class strength. They concluded that the utility of nutritional condition indices as predictors or indicators of near-term survival probability or recruitment remains to be demonstrated. 
Any attempt to forecast the probability of mortality from 1, or more than 1, of the suite of nutritional condition indices documented by Ferron \& Leggett (1994) makes the implicit assumption that the nutritional state of larvae at the time of sampling has a direct bearing on their survival potential. While intuitive and perhaps reasonable, the reality is that predictive relationships between the value of a particular nutritional index and the probability of mortality are unlikely to be simple and direct (Powell \& Chester 1985). For example, larval prey are often patchily distributed and larval fish feeding is a dynamic process that depends on numerous interacting biotic and abiotic variables (Dower et al. 1997). Furthermore, these variables can and often do change dramatically over short time-scales (Ferron \& Leggett 1994, Dower et al. 1997). Larvae classified as being in 'good' nutritional condition and commonly assumed to have a high probability of survival may also die from causes that are unrelated to their nutritional condition. Developmental abnormalities (Kjørsvik et al. 1990), external stress (e.g. toxins: Weis \& Weis 1995. Luoma 1996), etc. may compromise fitness or induce mortality independently of larval nutritional state. Thus, even indices that accurately determine the nutritional condition of larvae (and, thus, adequately address food limitation hypotheses) may ultimately be poor indices of survival potential. To date, the only reliable survival predictions based on nutritional condition indices are those which identify the threshold of irreversible starvation (i.e. 'point-of-no-return', Blaxter \& Hempel 1963). Larvae that are (correctly) so categorized are certain to die regardless of future feeding conditions. However, as Ferron \& Leggett (1994) have shown, the methods that best identify this threshold in larval fish are both labor-intensive and difficult to calibrate.

Larval buoyancy, or density (mass volume $e^{-1}$ ) change has been hypothesized to reflect the nutritional condition of larval fish (Blaxter \& Ehrlich 1974, Neilson et al. 1986, Sclafani et al. 1997). Starving larvae are typically less dense (more buoyant) than fed larvae of equal age (Blaxter \& Ehrlich 1974, Neilson et al. 1986, Frank \& McRuer 1989, Brousseau 1997). While considerable emphasis has been placed on the effects of nutrition on buoyancy changes in larval fish (e.g. Blaxter \& Ehrlich 1974, Ellertsen et al. 1980, Neilson et al. 1986, Yin \& Blaxter 1987a, Brousseau 1997), several other physiological and abiotic factors are known to influence buoyancy (Shelbourne 1957, Coombs 1981, Nissling et al. 1994, Ponwith \& Neill 1995, Sclafani et al. 1997). For example, Sclafani et al. (1997) demonstrated that starving larvae that experience osmotic breach and failure exhibit increased density $\left(\rho=g \mathrm{~cm}^{-3}\right)$ and that the magnitude of the density change greatly exceeded that exhibited by larvae that were experiencing nutri- tional effects alone. As a result, larvae experiencing osmotic breach and failure sank through the water column to the bottom stratum of their culture tanks. Increased sinking rates of larvae during advanced stages of starvation have also been reported by Blaxter \& Ehrlich (1974), Ellertsen et al. (1980) and Yin \& Blaxter (1987a). Increased density of a larva resulting from osmoregulation breach and failure is hypothesized to result from water loss to the hypertonic saltwater environment (Shelbourne 1957, Blaxter \& Ehrlich 1974, Sclafani et al. 1997). These osmotically induced changes in density have been Iargely ignored in analyses of the effects of nutrition on buoyancy and in the interpretation of buoyancy changes and their effects on spatial distributions and survival in situ.

Shelbourne (1957) hypothesized that starving larvae that were unable to meet their metabolic needs would experience an 'osmotic breach' and sink through the water column while dying. Sclafani et al.'s (1997) findings for larval cod supported Shelbourne's hypothesis regarding the fate of nutritionally depleted larvae. However, Sclafani et al. (1997) also found that osmotic breach and failure could occur in a proportion of wellnourished larvae (e.g. yolk-sac larvae). This suggests that osmotic breach and failure may have several causes. If, however, osmotic failure is a physiological endpoint that all larvae experience prior to death irrespective of their nutritional condition, then assays which reflect the osmotic condition of larval fish may be effective in predicting the near-term probability of mortality,

There have, however, been no controlled tests of the relationship between changes in larval density and near-term mortality $(<24 \mathrm{~h}$ ). Preliminary observations of starved larval cod (Sclafani et al. 1997) indicated that larvae with increased density resulting from os-

\section{Larval Mortality}

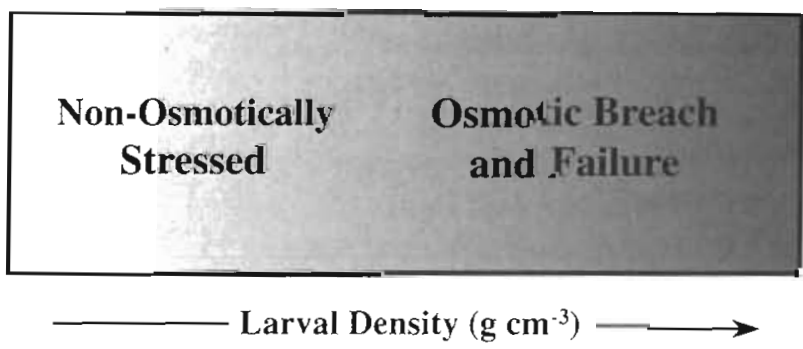

Fig. 1. Conceptual model of the expected relationship between changes in larval density and larval mortality. Larvae that are rot osmotically stressed and are experiencing nutritional effects will have a lower density relative to those experiencing osmotic breach and failure. Accordingly, larval mortality is expected to increase continuously, being lowest in larvae that have not experienced osmotic breach or failure and highest in those that have reached osmotic failure 
motic breach and failure experienced increased mortality. These observations led us to hypothesize a continuous and positive relationship between larval density and larval mortality. Specifically, we expect that larvae that are experiencing nutritional effects on density, but are not osmotically stressed, will have lower density and mortality relative to larvae that are experiencing osmotic breach and failure and are thus experiencing continuous increases in density while dying. The conceptual model depicted in Fig. 1 summarizes these hypothesized changes and their relationship to mortality. In this study, we sought to test the conceptual model of density and mortality and to develop a predictive model which relates the near-term probability of mortality of larvae to their density.

\section{METHODS AND MATERIALS}

Larval source and culture methods. We selected cod Gadus morhua L. larvae as our test species since nutritional and osmotic effects have been quantified for this species (Neilson et al. 1986, Sclafani et al. 1997) and because of their commercial and ecological importance (Rose 1993, Hutchings \& Myers 1994). We employed 2 batches of naturally fertilized cod eggs from separate spawning events (Batch 1: 21 March 1996, Batch 2: 15 April 1996) that were collected in egg baskets hung below the seawater outflow pipes of the broodstock tanks. These were maintained by Memorial University's Ocean Science Centre in Newfoundland, Canada. The eggs were rinsed with seawater containing streptomycin (50 $\mathrm{mg} \mathrm{l}^{-1}$ ) and penicillin-G (30 $\mathrm{mg} \mathrm{l}^{-1}$ ) and were placed in plastic bags containing filtered $(10 \mu \mathrm{m})$ seawater immediately after collection. Eggs were shipped by air-freight in an iced cooler (ca 1 to $3^{\circ} \mathrm{C}$ ) and arrived overnight at our laboratory at McGill University in Montreal, Quebec. There, they were gradually acclimated to Instant Ocean (Mentor, Ohio, USA) seawater that matched the salinity, temperature and $\mathrm{pH}$ of the adult spawning tanks (salinity $=32 \%$, temperature $=5^{\circ} \mathrm{C}$ and $\mathrm{pH}=8.0$ ). The eggs were incubated in three $120 \mathrm{l}$ static tanks which were siphoned daily and gently aerated. A constant $24 \mathrm{~h}$ light regime was maintained at 700 lux.

At the peak of hatching, a cohort of larvae of equal age was collected by pipette and transferred to eight 40 l static culture tanks $(h=30, l=49.5, w=26.5 \mathrm{~cm}$ ) that were maintained at the same temperature, salinity and $\mathrm{pH}$ as the egg incubators. Each culture tank was stocked with 1000 larvae. To protect against bacterial infections, a stock solution of Instant Ocean mixed with streptomycin (50 $\mathrm{mg} \mathrm{l}^{-1}$ ) and penicillin-G (30 $\left.\mathrm{mg} \mathrm{l}^{-1}\right)$ was added from a misting bottle on alternate days. Light levels were set at 700 lux and remained on $24 \mathrm{~h}$ a day for optimal feeding conditions (Puvanendran \& Brown 1998).

Four of the 8 culture tanks were randomly assigned the food treatment (fed treatment). Larvae in the remaining 4 tanks were starved (starved treatment). Twenty percent of the total volume of water was changed daily by siphoning from the bottom of each treatment tank. Dead larvae (opaque and curled) collected during siphoning were counted and discarded. The dead larvae provided an estimate of daily mortality for each tank.

Beginning at 2 days post-hatch (dph) we added marine algae (Isochrysis sp.) to the fed culture tanks daily for the first $5 \mathrm{~d}$ of the experiments to keep the water 'green'. From ages 4 to $18 \mathrm{dph}$, we also added Selco (Inve, Belgium) enriched rotifers (Brachionus plicatilis, ca $5 \mathrm{ml}^{-1}$ ) to the fed tanks. From ages $10 \mathrm{dph}$, we further added Artemia nauplii (ca $5 \mathrm{ml}^{-1}$ ) daily for the duration of the experiments. Prey concentrations were measured daily in each of the 4 fed tanks using $1 \mathrm{ml}$ pipette samples and enumerated to ensure their density remained relatively constant.

Complete yolk-sac absorption occurred at 7 and $8 \mathrm{dph}$, and total mortality in the starvation treatment tanks occurred at $15 \mathrm{dph}$ (Trial 1) for both egg batches. Trial 2 began on Day 16 of the experiments following total mortality for both egg batches. The 4 starved culture tanks were cleaned and replenished with $16 \mathrm{~d}$ old larvae (400 larvae $\operatorname{tank}^{-1}$ ) from the same cohort that were held in a stock tank maintained under conditions identical to those in the fed culture tanks. These replenished larvae were starved subsequent to their introduction on Day 16. Total mortality of larvae in Trial 2 occurred at $25 \mathrm{dph}$ (Batch 1) and $24 \mathrm{dph}$ (Batch 2).

Experimental design, sampling and density determination. We ran separate experiments for the 2 egg batches which we refer to herein as: (1) culture tank experiments (Batch 1) and (2) survival container experiments (Batch 2). The culture tank experiments provided an initial test of the relationship between larval density and mortality as well as a validation of treatment effects on these variables. The survival container experiments tested the relationship between larval density and percent mortality during a $24 \mathrm{~h}$ period following initial density determination. In both experiments, we sampled with respect to food and depth strata since osmotically stressed larvae increase in density and sink, while the non-osmotically stressed larvae are less dense and tend to remain in the upper zones of the water column (Sclafani et al. 1997). This approach increased the range of larval density and assured short-term mortality.

We estimated the vertical distribution of larvae within the culture tanks on alternate days by sampling with respect to 3 equal-depth strata: surface, middle 
and bottom. Sample sites within each tank were defined using a table of random numbers. On each sampling day we sampled randomly from a grid of eighteen $8 \mathrm{~cm}^{2}$ cells in each tank. We recorded the number of individuals within each vertical stratum $(10 \mathrm{~cm})$ of the sample (vertical sample). Twenty-five larvae were then removed from each vertical sample: 10 from the surface stratum, 10 from the bottom stratum and 5 from the middle stratum. Previous experiments indicated that only a small percentage of larval cod occupied the middle stratum in our culture tanks, thus reducing the sample size in this stratum (see Sclafani et al. 1997). Dead and opaque larvae were excluded from the sample. Viable larvae were placed in an isotonic linear density gradient column consisting of a mixture of Percoll (Pharmacia Fine Chemicals, Piscataway, NJ, USA), Ringer's isotonic saline solution and MS-222 (25 $\mathrm{mg} \mathrm{l}^{-1}$, Sigma Chemical, MO, USA) maintained at a temperature of $5^{\circ} \mathrm{C}$. These larvae sank to their depth of neutral density $\left(\rho=\mathrm{g} \mathrm{cm}^{-3}\right)$ in approximately 40 min. Larval density was determined by comparing the final depth of larvae in the column with the depth of calibration beads of known density (see Sclafani et al. 1997 for methodological details). New Percoll/Ringer density gradient columns were prepared every $5 \mathrm{~d}$.

Culture tank experiments. Treatment effect test: Mortality in the treatment tanks was assessed as the cumulative percent mortality for both food treatments. We compared the average cumulative percent mortality of the fed and starved treatments for each trial (Trial 1. 1 to $15 \mathrm{dph}$. Trial 2: 17 to $25 \mathrm{dph}$ ) using an analysis of covariance (ANCOVA: covariate = age) test for parallel slopes (Sokal \& Rohlf 1981). We expect that starved treatments will show increased mortality relative to the fed treatments.

We tested for differences in the average density of larvae in the fed and starved treatment tanks for each trial using an ANCOVA (covariate = age) test for parallel slopes. In this test, each replicate tank was considered the evaluation unit. We used depth-weighted averages to determine the average density of the larvae within each tank (Sclafani et al. 1997). In brief, the proportion of larvae in each of the 3 vertical strata was averaged for the 2 replicate vertical samples in each tank. The product of the average proportion of larvae in each stratum and the average densities of larvae in each stratum yielded an average density of larvae for each stratum. The resulting 3 weighted average density values from each stratum were averaged to yield a depth-weighted average density for each replicate tank. The depth-weighted average incorporated both osmotic and nutritional effects on larval density (Sclafani et al. 1997). We expect that the starved larvae will show an increased weighted average density rela- tive to the fed larvae that are not subjected to starvation-induced osmotic effects on density. Our a priori hypothesis is based on observations by Sclafani et al. (1997), where simultaneous increases in the density and abundance of starved larvae in the bottom stratum resulting from osmotic breach and failure increased their weighted average densities with starvation time. We do not expect to find such increases in the weighted average density of fed larvae.

Vertical distribution test: We determined the average proportion of larvae in each vertical stratum in the culture tank experiments for both food treatments on each sampling day from the 2 replicate vertical samples. We regressed the proportion of larvae in the bottom stratum (dependent variable) on larval age (independent variable) to determine whether systematic change in the numbers of larvae occurred in the bottom stratum with increasing age. Separate analyses were performed for fed and starved treatments and for each of the 2 starvation trials. In these tests, a significant positive linear trend would indicate a change in the larval distribution from the surface to the bottom. We expect a positive relationship for the starved treatments since starvation increases the proportion of larvae experiencing osmotic breach and failure, which increases their density and sinking (Sclafani et al. 1997). We do not expect to see this trend in the fed treatments.

Density and mortality: We calculated weighted average densities for each culture tank as described in 'Treatment effect test'. Percent mortality was determined from daily culture tank maintenance. We then averaged the density and mortality values of the 4 replicate culture tanks within each food treatment for each sampling day. The resulting average density values were correlated with the corresponding measures of daily percent mortality for the respective age and food treatments $(n=25)$. Linear regression analysis (Sokal \& Rohlf 1981) was used to test for a functional relationship between average density (independent variable) and mortality (dependent variable). We expect a positive relationship between average larval density and average larval mortality.

Survival container experiment. We tested for a relationship between initial larval density and their nearterm percent mortality ( $24 \mathrm{~h}$ ). On alternate days, we sampled 10 larvae from the surface and 10 larvae from the bottom stratum of a vertical sample taken from each tank. We measured the initial density of the larvae in the density gradient as described above (see 'Experimental design'). After removal from the density gradient, each group of 10 larvae were held separately in $250 \mathrm{ml}$ beakers (survival containers) containing Instant Ocean seawater for $24 \mathrm{~h}$ under conditions identical to the treatment tanks: temperature $=5^{\circ} \mathrm{C}$, salinity 
$=32 \%, \mathrm{pH}=8.0$ and light intensity $=700$ lux. The survival containers were labeled to indicate the food and strata the larvae were sampled from (i.e. Fed-Surface, Fed-Bottom, Starved-Surface, Starved-Bottom). Larvae sampled from fed tanks were offered the same food treatment and quantity as that in their culture tanks. Larvae originating from the starved tanks were starved. After $24 \mathrm{~h}$ of incubation, the larvae in each container were visually inspected for life signs (movement, heart-beat and transparency) under a stereo
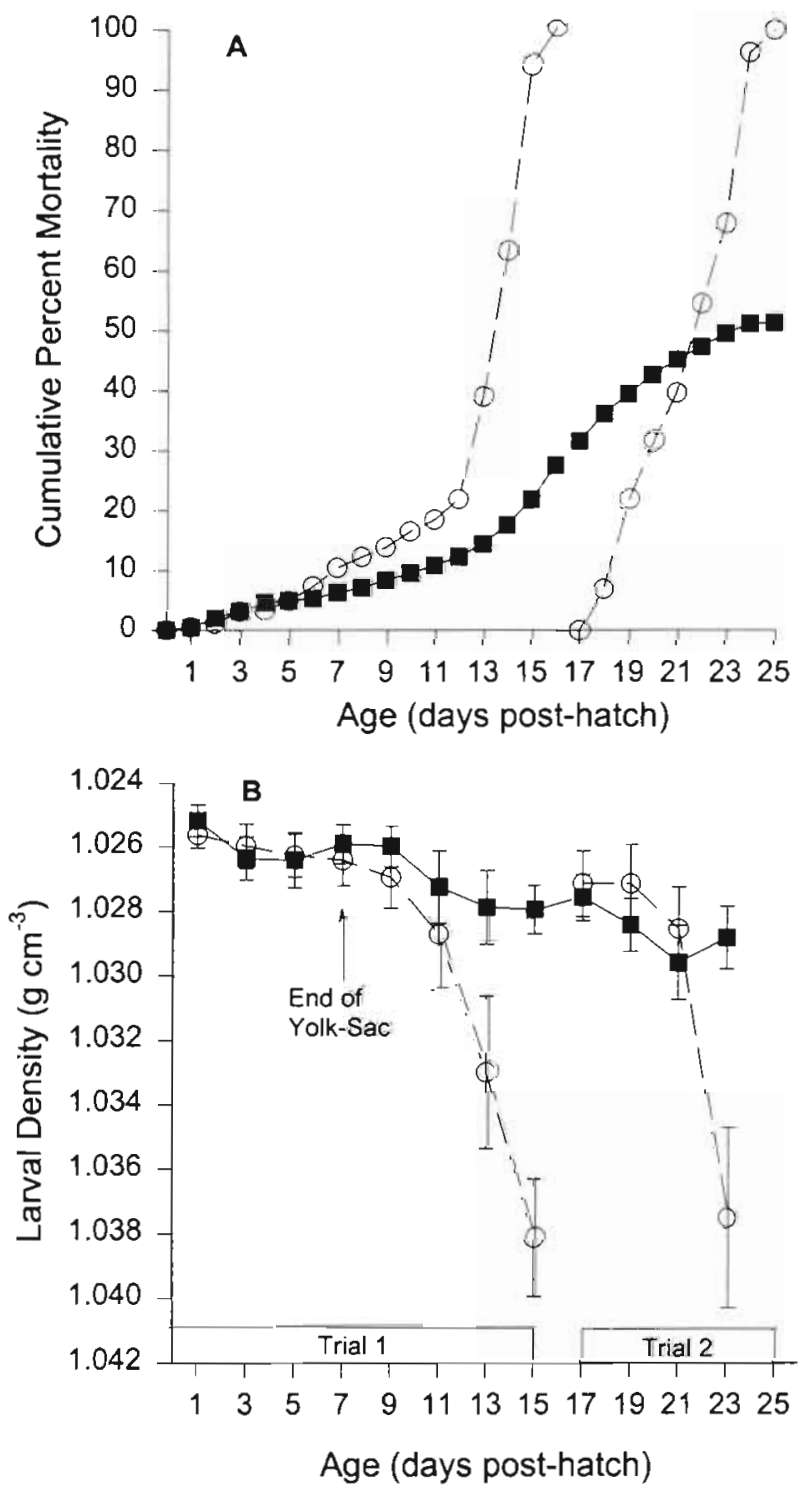

Fig. 2. Gadus morhua. (A) Cumulative daily percent mortality of larvae in the fed (D) and starved (O) culture tanks. (B) The depth-weighted average density $\left(\mathrm{g} \mathrm{cm}^{-3}\right)$ of fed (D) and starved (O) culture tanks (mean \pm 1 SEM). The starved culture tanks were replenished with fed larvae on Day 16, following complete mortality of the initial starved larvae (Trial 1) to create a second starvation trial (Trial 2) microscope $(25 \times)$. Each larva was scored as having survived if it showed 1 or more of these life-sign indicators. The proportion of survivors in each survival container was the proportion showing life signs divided by the total in the sample $(n=10)$.

We averaged the 10 initial larval densities in each food-strata treatment replicate on each sampling day (including yolk-sac larvae). We then averaged the 4 replicate containers for each food-strata group on each day sampled and correlated them with their similarly averaged percent mortality (100-survival\%) measures $(n=47)$. Linear regression analysis was used to test the hypothesis of a positive relationship between initial average density (independent variable) and average percent mortality (dependent variable) after $24 \mathrm{~h}$.

Comparison of experiments and predictive model. We tested for differences in the regression slopes for average density and average mortality between the culture tank and survival container experiments using ANCOVA (covariate $=$ density). We tested the null hypothesis of no difference between the slopes. If the null hypothesis was not rejected, the data were pooled to develop an overall predictive model for this functional relationship. We used linear and higher-order polynomial regressions (Kleinbaum et al. 1988) to test for the best predictive model. We used partial F-tests (Kleinbaum et al. 1988) to determine if higher-order polynomial regressions were significant, and the coefficients of determination were used as a means to assess the best-fitting regression.

In all statistical tests, normality was assessed using goodness-of-fit tests and homogeneity of variance was determined with Bartlett's tests and residual analyses (Sokal \& Rohlf 1981, Kleinbaum et al. 1988). We used $\alpha=0.05$ as our acceptance/rejection criteria. Statistical analyses were performed using Statistica (Statsoft Inc., Tulsa, OK, USA) software.

\section{RESULTS}

\section{Culture tank experiments}

Treatment effect tests

Starvation increased mortality rate. Several of the starved replicates experienced $100 \%$ mortality before 15 (Trial 1) and 25 (Trial 2) dph, thus reducing the number of replicates at these ages. The average cumulative percent mortality in the fed and starved treatments differed significantly in both trials (Fig. 2A, ANCOVA Trial 1: $F_{1,30}=18, \mathrm{p}<0.001$; Trial 2: $F_{1,14}=$ 175, $\mathrm{p}<0.00001$ ). Larvae in the fed treatment tanks had a lower mortality rate (slope of linear regression of cumulative $\%$ mortality on age: $2.3 \% \mathrm{~d}^{-1}$ ) than those in 
the starved treatment in both trials (Trial 1: $5.4 \% \mathrm{~d}^{-1}$, Trial 2: $13.1 \% \mathrm{~d}^{-1}$ ). These results are consistent with our expectations for the effects of food on larval mortality.

Starved larvae showed increased weighted average density with starvation time and were significantly more dense than the fed treatments in Trial 1 (Fig. 2B, ANCOVA: $\left.F_{1,56}=19.7, \mathrm{p}<0.0001\right)$ and Trial $2\left(F_{1,28}=\right.$ 16.4, $\mathrm{p}<0.001)$. These results are consistent with our expectations for the treatment effects on weighted average densities

\section{Vertical distribution}

In addition to increased mortality and density in the starved tanks, the proportion of larvae in the bottom stratum increased with starvation time. Few larvae $(<15 \%$ across all ages) were observed in the middle stratum in the starved treatment (Fig. 3). This is consistent with the results of our earlier experiments (Sclafani et al. 1997). The proportion of larvae in the bottom stratum of the starved tanks increased linearly with increasing starvation time in Trial $1\left(\mathrm{r}^{2}=0.62, F_{1,24}=\right.$ $40.3, \mathrm{p}<0.0001)$ and Trial $2\left(\mathrm{r}^{2}=0.66, F_{1,17}=30, \mathrm{p}<\right.$ $0.0001)$.

In the fed treatment, few larvae also occupied the middle stratum in Trial 1, but showed increasing homogeneity with depth in Trial 2 (Fig. 3). The proportion of fed larvae in the bottom stratum did not show a systematic change with age for larvae in Trial $1\left(\mathrm{r}^{2}=\right.$ $\left.0.08, F_{1,27}=2.3, \mathrm{p}=0.14\right)$ or Trial $2\left(\mathrm{r}^{2}=0.01, F_{1,19}=0.3\right.$, $p=0.6$ ). These observations are also consistent with our expectations for food effects on larval vertical distributions in the culture tanks.

\section{Density and mortality}

A strong, positive linear relationship $\left(r^{2}=0.79, F_{1,23}=\right.$ 88, $\mathrm{p}<0.00001$ ) was observed between average larval density and average percent mortality in the larvae sampled from the culture tanks (Fig. 4). The relationship was described by the following linear model: Average \% Mortality $=-6719+6556$ (Average Density). Culture tanks that had lower weighted average densities were associated with decreased mortalities, while those with higher average density showed increased mortalities.

\section{Survival container experiment}

Short-term, the survival container experiment indicated mortality was higher in the bottom strata. A strong, positive linear relationship $\left(\mathrm{r}^{2}=0.78, F_{1,46}=\right.$ 164, $\mathrm{p}<0.0001$ ) between average initial larval density and average percent mortality after $24 \mathrm{~h}$ was also observed in the survival container experiment (Fig. 4). The relationship was described by the following linear model: Average \% Mortality $=-5147+5023$ (Average Density). The survival containers with lower initial average densities had lower short-term average mortality, whereas those with high initial densities experienced higher short-term mortality. The containers having the greatest average densities and average mortalities were sampled from the bottom strata of the starved treatments just prior to $100 \%$ mortality in Trials 1 and 2 .
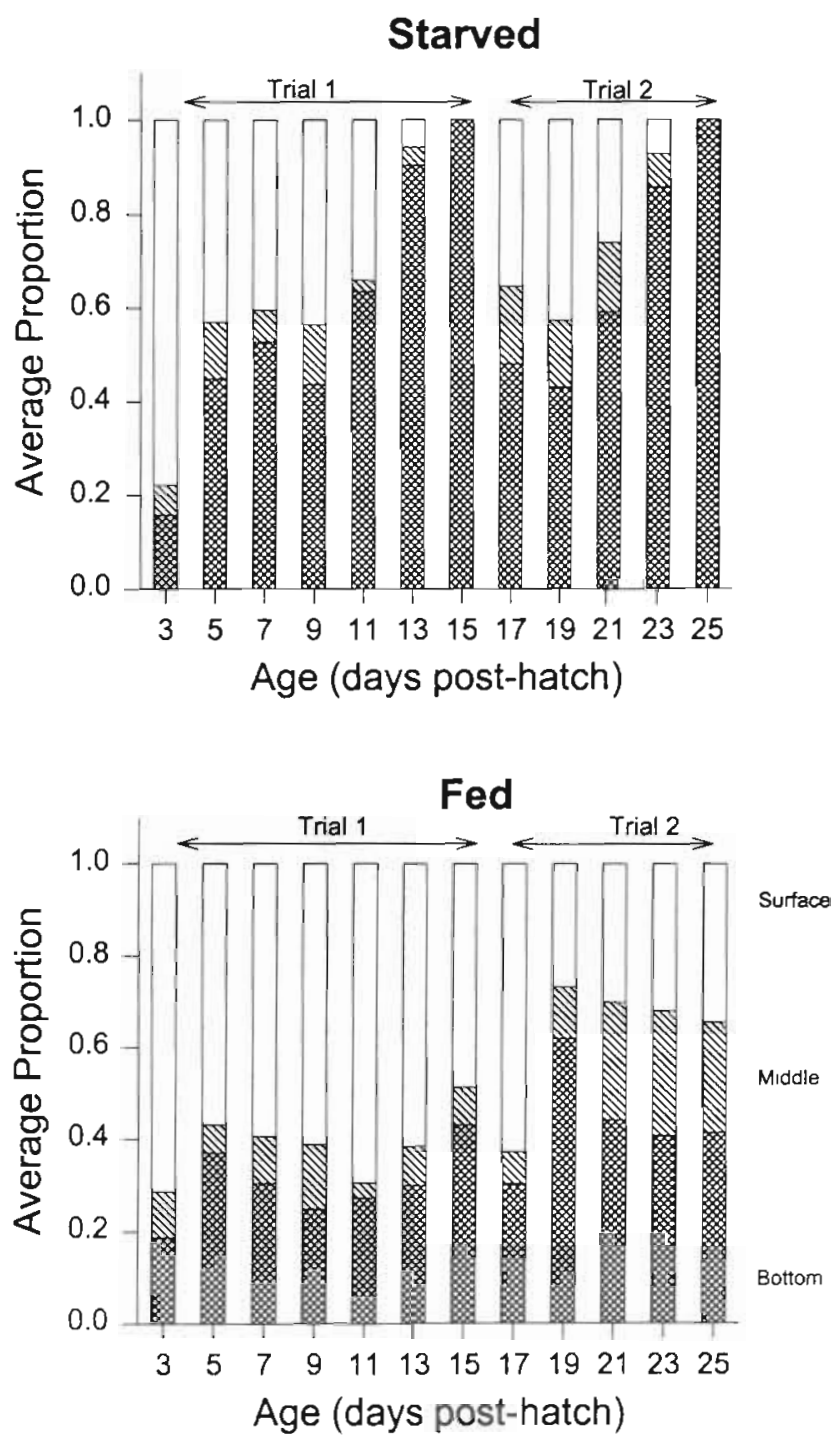

Fig. 3. Average proportion of starved and fed larval cod occurining in the surface (open), middle (diagonal) and bottom (cross-hatched) depth strata of the culture tanks 


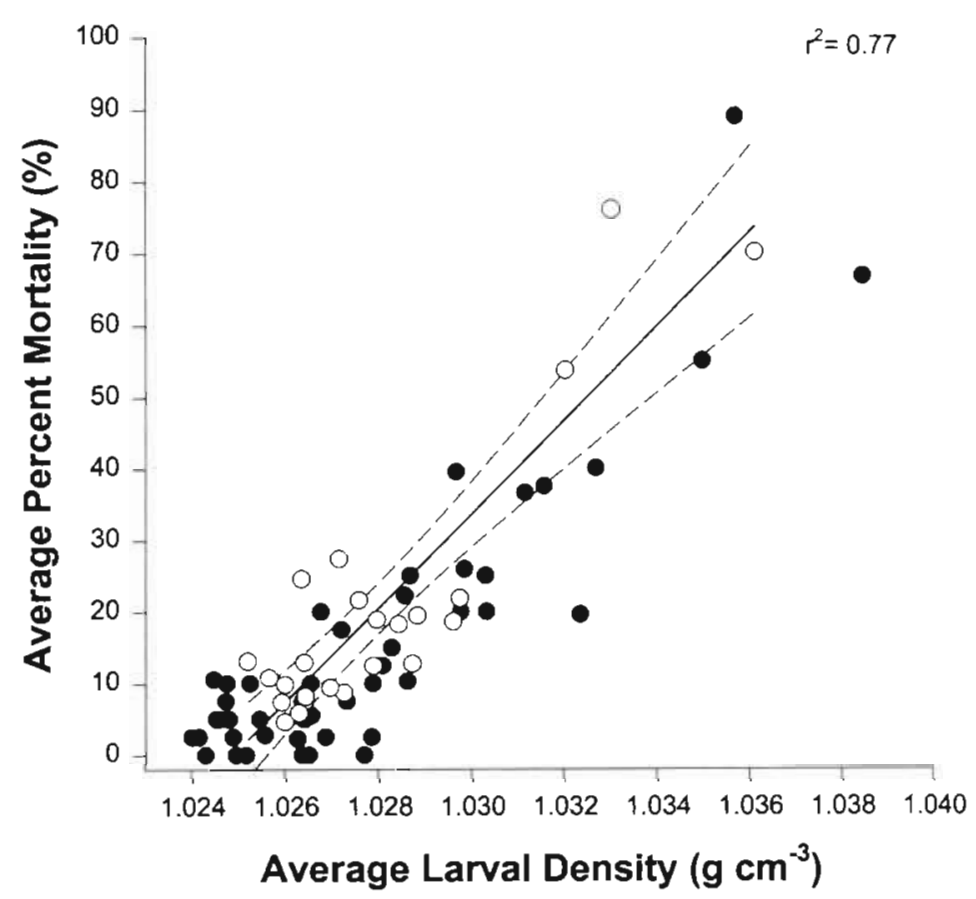

Fig. 4. Relationship between the average larval density and average percent larval mortality within the culture tank $(0)$ and survival container (1) experiments. (-) Estimate of the best-fit linear regression on the pooled data $\tilde{a}_{i}(--) 95 \%$ confidence intervals

hypothesized that larval density should be positively and continuously related to larval mortality (Fig. 1). The significant positive linear relationships observed between average density and average mortality in 2 related, but different, experiments support this hypothesis. These relationships were strong and consistent, indicating that the link between average density and average near-term mortality is robust. First- and second-order polynomial regressions applied to the pooled data from the 2 experiments were highly significant and explained most of the variation in the data. The differences between their respective coefficients of determination was small (first-order: 0.77 , second-order: 0.80 ) and the second-order relationship fell within the $95 \%$ confidence limits of the first-order regression throughout most of the range of the data. The second-order polynomial regression did, however, fit the data better at the density and mortality extremes. It is possible that the second-order model may better reflect 2 different rate changes in mortality and density associated with nutritional and osmotic effects. The density of larval cod having densities $<1.029 \mathrm{~g} \mathrm{~cm}^{-3}$ are primarily influenced by nutritional effects (Neilson et al. 1986, Sclafani et al. 1997). The

\section{Comparison of density and mortality experiments}

The slopes between the culture tanks and survival container experiments for average density and average mortality did not differ (ANCOVA: $F_{1,68}=3.6, \mathrm{p}>$ $0.05)$, and we pooled the data. A linear regression on the pooled data yielded the following significant $\left(\mathrm{r}^{2}=\right.$ $0.77, F_{1.70}=238, \mathrm{p}<0.0001$ ) relationship: Average $\%$ Mortality $=-5549+5415.7$ (Average Density). A second-order polynomial regression on the pooled data was also highly significant and improved the fit $\left(\mathrm{R}^{2}=0.80, F_{2,69}=133, \mathrm{p}<0.0001\right)$ with the following equation: Average \% Mortality $=222536.5$ 437549.3 (Average Density) + 215068 (Average Density $)^{2}$. The second-order polynomial fit the data better at the density and mortality extremes; however, it fell within the $95 \%$ confidence limits of the first-order model throughout most of its range.

\section{DISCUSSION}

Since changes in larval density resulting from nonosmotic factors (i.e. nutritional effects) and osmotic breach and failure can be organized on a single axis (the effects of osmotic breach and failure overwhelming those of nutritional effects; Sclafani et al. 1997), we better fit exhibited by the second-order polynomial at densities $>1.033 \mathrm{~g} \mathrm{~cm}^{-3}$ (i.e. approximate value exceeding the density of mortality at $50 \%$, Fig. 4) may reflect the fact that mortality accelerates in a nonlinear fashion at densities associated with osmotic breach and failure. While the second-order model provides a marginally better fit to the data, for the purposes of predicting near-term mortality from density measures we recommend the simpler first-order regression model because of its ease of application.

The density values associated with larvae that exhibited low mortality $(<30 \%)$ exhibited considerable scatter. This reflects variability resulting from the combination of food and strata treatments employed in this study. Additional factors that have also been shown to influence the buoyancy of eggs and larvae of marine fish, and could be averaged in the data, include: developmental stage, size, maternal source, or temperature and salinity (e.g. Kjesbu et al. 1992, Nissling et al. 1994, Ponwith \& Neill 1995). These factors can be complex (Sclafani et al. 1997); however, the magnitude of the density changes induced by these factors are much lower than those associated with osmotic breach and failure, and are, therefore, not expected to influence the character of the positive relationship between density and mortality we report. Moreover, our findings are consistent with those from other studies that have 
shown increased sinking rates of larvae during the advanced stages of starvation (e.g. Blaxter \& Ehrlich 1974, Ellertsen et al. 1980, Yin \& Blaxter 1987a). What distinguishes our findings is that, while previous studies have noted increases in the density and sinking rates of moribund eggs and larvae (e.g. Blaxter \& Ehrlich 1974, Ellertsen et al. 1980, Coombs 1981, Yin \& Blaxter 1987a), ours is the first study to document the nature of the relationship between density and the probability of mortality over a broad range of densities.

\section{Critical density}

The consistency and strength of the relationship between larval density and larval mortality indicates that the transition from non-osmotic stress to osmotic breach and failure in larval cod is continuous, and that larval density can be used as a reliable predictor of near-term mortality. Drawing on the approach used in the analysis of indicators of stress (e.g. LC50; Sprague 1990), we suggest that larval density at $50 \%$ mortality, as determined from an appropriate regression model, can be employed as a benchmark representing that density beyond which larvae can reliably be assumed to have experienced osmotic breach and failure, which leads ultimately to death.

In our determination of this benchmark, or 'critical' density, we employed the pooled data from the separate experiments in which the results were very similar. We were unfortunately not able to control the independent variable (density) in a manner equivalent to experiments involving the test of mortality effects of a chemical toxin (e.g. logarithmic dilutions). We did, however, employ logistic regressions (Kleinbaum et al. 1988) which are commonly utilized in aquatic toxicological studies for such estimates (Sprague 1990). In these logistic regressions we coded survival 0 if mortality was $<50 \%$ and 1 if mortality was $>50 \%$. Inverse predictions were made from each of the best-fitted regression equations to calculate the density of larvae at $50 \%$ mortality and their $95 \%$ confidence intervals (Sokal \& Rohlf 1981). The 'critical' density for cod lar-

Table 1 Comparison of linear, second-order polynumial and logistic regression model predictions for the density of larvae at $50 \%$ mortality !'critical' density) and the $95 \%$ confidence limits (lower and upper bounds)

\begin{tabular}{|lccc|}
\hline $\begin{array}{l}\text { Regression } \\
\text { model }\end{array}$ & $\begin{array}{c}\text { Critical } \\
\text { density }\left(\mathrm{g} \mathrm{cm}^{-3}\right)\end{array}$ & $\begin{array}{c}\text { Lower } \\
\text { bound }\end{array}$ & $\begin{array}{r}\text { Upper } \\
\text { bound }\end{array}$ \\
\hline Linear & 1.0338 & 1.0304 & 1.0373 \\
Second-order polynomial & 1.0338 & 1.0312 & 1.0360 \\
Logistic & 1.0337 & 1.0328 & 1.0354 \\
\hline
\end{tabular}

vae and their 95\% confidence limits for the 3 regressions are listed in Table 1. The linear and second-order polynomial regressions produced benchmark or 'critical' density values that were identical. Benchmark density values calculated from the logistic regression were slightly lower The $95 \%$ confidence limits calculated for critical densities from the first- and secondorder polynomial regressions, and the logistic regres. sion overlapped. Since the 3 regression methods employed resulted in essentially identical densities at $50 \%$ mortality, we chose the simpler linear model to estimate the 'critical' density value in our experiments. This determination indicates that larval cod having density values $<1.0338 \mathrm{~g} \mathrm{~cm}^{-3}$ have a $<50 \%$ probability of dying over $24 \mathrm{~h}$. Those with values $>1.0338 \mathrm{~g}$ $\mathrm{cm}^{-3}$ (judged to have exceeded the benchmark, or 'critical' density) have a $>50 \%$ probability of dying within $24 \mathrm{~h}$. Other 'critical' density values could be chosen depending on the level of certainty required regarding survival probability.

An important aspect of our experimental design was sampling with respect to depth strata. This was employed to maximize the range of larval. densities associated with nutritional and osmotic effects (Sclafani et al. 1997). This method is based on the premise that starved larvae experience a higher incidence of asmotic breach and failure, have increased density and sink more rapidly through the water column relative to those that are experiencing nutritional effects only, which tend to remain in the water column. It was important that we validate this premise. Larvae in the starved treatments showed increased mortality relative to those in the fed treatments. This was consistent with our expectations for the effects of food in the culture tank experiments and is commonly observed in marine larval fish culture (e.g. Yin \& Blaxter 1987b). The vertical distribution data in the culture tanks were also consistent with our expectations; the proportion of starved larvae in the bottom stratum increased with starvation time, while the fed treatments displayed a more even distribution of larvae. These observations also explain the results of the food treatment effects on larval density in the culture tank experiments. The weighted average densities of the starved treatments exceeded those of the fed treatments because of the simultaneous increase in the proportion of larvae in the bottom stratum that were experiencing increased density from starvation-induced osmotic breach and failure with increased starvation time (Sclafani et al. 1997). The fed treatments were not influenced by such changes in depth distribution or density; hence, their weighted averages remained lower. These results indicate that increases in larval density resulting from osmotic breach and failure overwhelmed those of nutritional effects. This is consistent with the findings 
of an earlier study (Sclafani et al. 1997). These findings also validate the use of stratified sampling to examine the relationship between larval density and mortality.

\section{Applications}

We believe the relationship between density and mortality described above has potential for use in both laboratory and in situ studies of larval mortality. The density assay we describe is rapid (typically $<60 \mathrm{~min}$ ) and 'non-destructive'. Furthermore, the procedure used to gain density measures does not appear to induce or accelerate death of larvae during, or after, the measures are taken, and facilitates the acquisition of short-term survival/mortality data for individual larvae. In support of this observation, Coombs (1981) observed that mackerel Scomber scombrus eggs hatched successfully after several days of continual buoyancy monitoring in saltwater density gradient columns. Coombs (1981) also showed that density gradients similar to those we employed in this study are stable when used at sea, thereby facilitating their use in in situ studies. It is very important to note, however, that in applying this approach to in situ studies, the collection methods employed must minimize or avoid the creation of osmotic stress in the sampled larvae. This is unlikely to be achieved if conventional survey gear and deployment protocols are used. However, modified conventional plankton collectors (oversized codend) and deployment methods (slower and shorter vertical net tows; Dower et al. 1998) or light trap collectors (Thorrold 1993) can yield unbiased samples. A test of the in situ utility of the density bioassay detailed here, thus appears warranted. If successful, the 'critical' density bioassay could be applied to abundance surveys to provide corrected estimates of the numbers of larvae sampled at any given time that are viable within a defined time horizon (24 h). To date this is the first condition index providing this potential.

\section{Interpreting in situ vertical distributions}

We acknowledge that the differences in spatial scale and physical conditions (e.g. turbulence) between our laboratory experiments and those encountered in situ are substantial. Nevertheless, we expect that the passive effects of buoyancy observed in this study will influence the vertical distribution patterns of larvae that are commonly attributed to feeding or predator avoidance behaviours (reviewed by Neilson \& Perry 1990). Field studies of larval haddock Melanogrammus aeglefinus by Frank \& McRuer (1989) and simulations by Sclafani et al. (1993) on larval cod suggest that nutritional effects on buoyancy could account for the observed vertical distributions of these species. However, none of these studies accounted for the effects of osmotic breach or failure on the vertical distributions observed or modelled. Thus, in these studies, interpretations of the vertical distribution data were limited to feeding, 'good' condition larvae, and non-feeding, 'poor' condition individuals. A more accurate representation would include a category for osmotically stressed larvae that are sinking and near death. The vertical distributions we observed in the present study were primarily bimodal. Over the larger range of temperatures, salinities and depths characteristic of the in situ situation, larvae exhibiting higher densities may form a more continuous distribution. Regardless, our findings suggest that average density estimates obtained over the observed vertical distribution of larvae could be used to predict their survival probabilities by depth strata. Our data lead us to speculate that there will be a relationship between depth and average density of post yolk-sac larvae and that this will be directly related to their probability of survival. While the findings reported here represent little more than a beginning, especially when applied to in situ events, they do suggest that the study of larval density can provide estimates from nutritional and other non-predation related causes. This, in turn, opens the door for isolating and quantifying mortality induced by predation.

Acknowledgements. We thank J. Brown, L. Crim, C. Wilson, D. Boyce and T Keough of Memorial University, St. John's, Newfoundland, who supplied the cod eggs used in this study C. Potvin and $J$. Rasmussen provided laboratory space. $M$. Romer and C. Rooney provided assistance in maintaining environmental chambers. Comments on the manuscript by $L$. Brousseau and anonymous reviewers greatly improved its quality. S. Barbeau, L. Brousseau, T. Herra, S. Hum, and G. Lee provided technical assistance. This paper forms part of the PhD thesis of M.S. at McGill University, Montreal, Quebec, Canada. The research was funded by operating grants to W.C.L. from the Natural Sciences and Engineering Research Council of Canada, the Ocean Production Enhancement Network (OPEN), Fisheries and Oceans, Canada, and Groupe interuniversitaire de recherches océanographiques du Québec (GIROQ).

\section{LITERATURE CITED}

Bisbal GA, Bengtson DA (1995) Description of the starving condition in summer flounder, Paralichthys dentatus, early life history stages. Fish Bull US 93:217-230

Blaxter JHS, Ehrlich KF (1974) Changes in behaviour during starvation of herring and plaice larvae. In: Blaxter JHS (ed) The early life history of fish. Springer-Verlag, New York, p 575-588

Blaxter JHS, Hempel G (1963) The influence of egg size on herring larvae (Clupea harengus L.). J Cons Int Explor Mer 28:211-240 
Brousseau L (1997) The effectiveness of morphometrics and buoyancy in determining larval nutritional condition of haddock (Melanogrammus aeglefinus), and their suitability for use in a commercial operation. Masters thesis, Simon Fraser University, Burnaby, BC

Clemmesen CM (1987) Laboratory studies on RNA/DNA ratios of starved and fed herring (Clupea harengus) and turbot (Scophthalmus maximus) larvae. J Cons Int Explor Mer 43:122-128

Clemmesen C (1993) Improvements in the fluorimetric determination of the RNA and DNA content of individual marine fish larvae. Mar Ecol Prog Ser 100:177-183

Coombs SH (1981) A density-gradient column for determining the specific gravity of fish eggs, with particular reference to eggs of the mackerel Scomber scombrus. Mar Biol 63:101-106

Dower JF, Miller TJ, Leggett WC (1997) The role of microscale turbulence in the feeding ecology of larval fish. Adv Mar Biol 31:169-220

Dower JF, Pepin P, Leggett WC (1998) Enhanced gut fullness and apparent shift in size selectivity by radiated shanny (Ulvaria subbifurcata) larvae in response to increased turbulence. Can J Fish Aquat Sci 55:128-142

Ellertsen B, Solemdal P, Strømme T, Tilseth $S$, Westgård $T$, Moksness E, Øiestad V (1980) Some biological aspects of cod larvae (Gadus morhua L.). FiskDir Skr Ser HavUnders $17: 29-47$

Ferron A, Leggett WC (1994) An appraisal of condition measures for marine fish larvae. Adv Mar Biol 30:217-303

Frank KT, McRuer JK (1989) Nutritional status of field-collected haddock (Melanogrammus aeglefinus) larvae from southwestern Nova Scotia: an assessment based on morphometric and vertical distribution data. Can J Fish Aquat Sci 46 (Suppl 1):125-133

Hutchings JA, Myers RA (1994) What can be learned from the collapse of a renewable resource? Atlantic cod, Gadus morhua, off Newfoundland and Labrador. Can J Fish Aquat Sci 51:2126-2146

Kjesbu OS, Kryvi H, Sundby S, Solemdal P (1992) Buoyancy variations in eggs of Atlantic cod (Gadus morhua L.) in relation to chorion thickness and egg size: theory and observations. J Fish Biol 41:581-599

Kjørsvik E, Mangor-Jensen A, Holmefjord I (1990) Egg quality in fishes. Adv Mar Biol 26:71-113

Kleinbaum DG, Kupper LL, Muller KE (1988) Applied regression analysis and other multivariable methods. PWS-Kent Publishing Co, Boston

Leggett WC, Deblois E (1994) Recruitment in marine fishes: is it regulated by starvation and predation in the egg and larval stages? Neth J Sea Res 32:119-134

Lochmann SE, Maillet GL, Frank KT, Taggart CT (1995) Lipid class composition as a measure of nutritional condition in individual larval Atlantic cod (Gadus morhua). Can J Fish Aquat Sci 52:1294-1306

Luoma SN (1996) The developing framework of marine ecotoxicology: Pollutants as a variable in marine ecosystems? J Exp Mar Biol Ecol 200:29-55

Neilson JD, Perry RI (1990) Diel vertical migrations of marine fishes: obligate or facultative process? Adv Mar Biol 26 : $115-168$

Neilson JD, Perry RI, Valerio P, Waiwood KG (1986) Condition of Atlantic cod Gadus morhua larvae after the transition to

Editorial responsibility: Kenneth Sherman (Contributing Editor), Narragansett, Rhode Island, USA exogenous feeding: morphometrics, buoyancy and predator avoidance. Mar Ecol Prog Ser 32:229-235

Nissling A, Kryvi $H$, Vallin L. (1994) Variation in egg buoyancy of Baltic cod Gadus morhua and its implications for egg survival in prevailing conditions in the Baltic Sea. Mar Ecol Prog Ser 110:67-74

O'Connell CP (1980) Percentage of starving northern anchovy Engraulis mordax, larvae in the sea as estimated by histological methods. Fish Bull US 78(2):475-489

O'Connell CP (1981) Estimation by histological methods of the percent of starving larvae of the northern anchovy (Engraulis mordax) in the sea. Rapp P-V Réun Cons Int Explor Mer 178:357-360

Ponwith BJ. Neill WH (1995) The influence of incubation salinity on the buoyancy of red drum eggs and yolk sac larvae, J Fish Biol 46:955-960

Powell AB, Chester AJ (1985) Morphometric indices of nutritional condition and sensitivity to starvation of spot larvae. Trans Am Fish Soc 114:338-347

Puvanendran V, Brown JA (1998) Effect of light intensity on the foraging and growth of Atlantic cod larvae: interpopulation difference? Mar Ecol Prog Ser 167:207-214

Rose GA. (1993) Cod spawning on a migration highway in the north-west Atlantic. Nature 366:458-461

Sclafani M, Taggart CT, Thompson KR (1993) Condition, buoyancy and the distribution of larval fish: implications for vertical migration and retention. J Plankton Res 15: $413-435$

Sclafani M, Stirling G, Leggett WC (1997) Osmoregulation, nutritional effects and buoyancy of marine larval fish: a bioassay for assessing density changes during the earliest life history stages. Mar Biol 129:1-9

Shelbourne JE (1957) The feeding and condition of plaice larvae in good and bad plankton patches. J Mar Biol Assoc UK 36:539-552

Sokal RR, Rohlf FJ (1981) Biometry. The principals and practice of statistics in biological research, 2nd edn. WH Freeman and Company, New York

Sprague JB (1990) Aquatic toxicology. In: Schreck CB, Moyle PB (eds) Methods for fish biology. American Fisheries Society, Bethesda, MD, p 491-528

Theilacker GH (1978) Effect of starvation on the histological and morphological characteristics of jack mackerel, Trachurus symmetricus, larvae. Fish Bull US 76:403-414

Theilacker GH (1986) Starvation-induced mortality of young sea-caught jack mackerel, Trachurus symmetricus, determined with histological and morphological methods. Fish Bull US 84:1-17

Thorrold SB (1993) Post-larval and juvenile Scombrids captured in light traps: preliminary results from the central Great Barrier. Reef lagoon. Bull Mar Sci 52:631-641

Weis JS, Weis P (1995) Swimming performance and predator avoidance by mummichog (Fundulus heteroclitus) larvae after embryonic or larval exposure to methylmercury. Can J Fish Aquat Sci 52:2168-2173

Yin MC, Blaxter JHS (1987a) Temperature, salinity tolerance, and buoyancy during early development and starvation of Clyde and North Sea herring, cod and flounder larvae. J Exp Mar Biol Ecol 107:279-290

Yin MC, Blaxter JHS (1987b) Feeding ability and survival during starvation of marine fish larvae reared in the laboratory. J Exp Mar Biol Ecol 105:73-83

Submitted: February 5, 1999; Accepted: August 17, 1999

Proofs received from author(s): February ?, 2000 